\title{
Rancang Bangun Pembangkit Pulsa Tiga Sensor Ultrasonik Untuk Pendeteksi Kecacatan Beton Berbasis Mikrokontroler
}

\author{
Setyo Swasoko*1, Abdul Rouf ${ }^{2}$ \\ ${ }^{1}$ Prodi Elektronika dan Instrumentasi, DIKE, FMIPA UGM, Yogyakarta, Indonesia \\ ${ }^{2}$ Departemen Ilmu Komputer dan Elektronika, FMIPA UGM, Yogyakarta, Indonesia \\ e-mail: *1 setyoswasoko@gmail.com, ${ }^{2}$ rouf@mail.ugm.ac.id
}

\begin{abstract}
Penelitian NDT dilakukan untuk mendeteksi adanya cacat pada suatu benda padat. Metode ini dilakukan karena tidak merusak benda yang diuji. Berbagai cara penelitian NDT juga telah banyak diteliti, salah satunya adalah multi-transmitter. Penggunaan multitransmitter memungkinkan pengguna lebih efisien dalam scanning cacat karena jangkauan sensor yang makin luas. Dengan kelebihannya dibandingkan sumber pulsa lain seperti AFG, diantaranya portable, bahaya radiasi kecil, harga relatif lebih murah, lebih banyak variasi frekuensi yang dapat dihasilkan, dan penggunaan catu daya yang kecil maka digunakan mikrokontroler sebagai pembangkit sinyal.

Pembangkit gelombang ultrasonik yang dipancarkan tiga transmitter sebesar $40 \mathrm{kHz}$ diinputkan melalui serial PC ke mikrokontroler dan diubah menjadi sinyal sinus dengan modul AD9850. Amplitudo frekuensi dari AD9850 dikuatkan dayanya dengan menggunakan LM386, dan dikuatkan lagi tegangannya dengan menggunakan tranformator inti ferit. Untuk memilih sensor mana yang hidup, digunakan switch.

Dari penelitian diperoleh beberapa kesimpulan. Output tegangan maksimal dari modul AD9850 adalah 1,04 V. Output tegangan maksimal LM386 adalah $\pm 14 \mathrm{~V}$. Dan output tegangan maksimal trafo inti ferit adalah $\pm 170 \mathrm{~V}$. Transmitter yang efektif memancarkan tegangan adalah transmitter milik SRF04 dan tegangan input maksimal adalah $\pm 60 \mathrm{~V}$. Amplitudo gelombang akan mengecil apabila jarak pantul semakin jauh, sebaliknya amplitudo semakin besar apabila jarak pantul semakin dekat.
\end{abstract}

Kata kunci - pembangkit sinyal ultrasonik, tiga sensor ultrasonik, penguat daya, penguat tegangan

\section{Abstract}

NDT Research conducted to detect any defects on a solid materials. This method is done because not damage the object being tested. Various methods of NDT research also studied, one of which is a multi-transmitter. Multi-transmitter more efficient in scanning objects defective because a more extensive range of sensors. Prioritizing advantages compared with other pulse sources such as AFG, including portable, small radiation, the price relatively cheaper, variety of frequencies that can be generated, and smaller power supplies will be used microcontroller as signal generator.

With this concept, generating ultrasonic waves $40 \mathrm{kHz}$ emitted by three transmitter input from serial PC to microcontroller and converted into analog signal AD9850 module. Amplitude of the frequency of AD9850 strengthened using LM386, and strengthened again using transfomator ferrite core. And choose sensor, used switches.

From research conducted by a few conclusions. Maximum of output voltage AD9850 module is $1.04 \mathrm{~V}$. Maximum output voltage of LM386 is $\pm 14 \mathrm{~V}$ and maximum voltage output of ferrite transformator is $\pm 170 \mathrm{~V}$. The effective transmitter is SRFO4 and maximum input voltage is $\pm 60 \mathrm{~V}$. Amplitude of wave will be smaller if reflection distance farther, otherwise amplitude increases if the reflection distance is closer.

Keywords - ultrasonic wave generator, three ultrasonic sensors, power amplifier, voltage amplifier

Received April 23 ${ }^{\text {th }}, 2017$; Revised June 15 ${ }^{\text {th }}$, 2017; Accepted October $30^{\text {th }}, 2017$ 


\section{PENDAHULUAN}

B enda padat dalam proses pembuatannya tidak bisa terlepas dari masalah kecacatan fisik atau kerusakan yang terjadi di dalam benda tersebut [1]. Kerusakan tersebut dapat menjadi resiko yang membahayakan serta menimbulkan kerugian. Oleh karena itu, perlu dilakukannya uji kualitas terhadap benda padat tersebut guna menanggulangi resiko yang membahayakan serta menimbulkan kerugian.

Uji kualitas pada suatu benda padat biasanya dilakukan bila kita ingin tahu apakah ada cacat atau tidak di dalam benda padat tersebut. Informasi ada atau tidak adanya cacat ini sudah cukup digunakan sebagai dasar dari suatu pengambilan keputusan, misalnya benda padat yang ada cacatnya dipotong dan dibuang atau dilebur kembali. Ada beberapa komponen penting dalam uji kualitas terhadap benda padat salah satunya adalah ukuran kecacatan, karena ukuran kecacatan dapat menjadi indikator apakah benda padat tersebut layak digunakan atau tidak.

Ukuran kecacatan di dalam benda padat dapat diketahui dengan cara uji tak merusak (Non Destructive Test) [2]. Salah satu metode pada NDT adalah dengan metode Ultrasonic test. Seperti yang pernah dikemukaan oleh Yatarif (2008) bahwa untuk mengetahui kondisi didalam suatu bahan baku tersebut apakah dalam kondisi baik atau mengalami kecacatan atau tidak, dapat dilakukan dengan cara pengujian Non Destructive Test (NDT) yaitu dengan cara ultrasonic test untuk melihat cacat (keretakan) pada bagian dalam suatu benda yang meliputi jarak keretakan dari permukaan, bentuk keretakan dan ukuran keretakan [3]. Ultrasonik juga dapat digunakan untuk mendeteksi cacat permukaan yang rusak yang pada slot baja atau yang disebut dengan duralmunium [4].

Sensor ultrasonik dapat mendeteksi kecacatan objek dengan cara memancarkan gelombang ultrasonik (40 kHz) dengan tegangan tinggi dan diamati hasil penurunan tegangan yang terjadi. Apabila terjadi kenaikan tegangan dari sinyal yang dipancarkan, maka di dalam obyek tersebut terdapat cacat.

Perkembangan NDT dengan sensor ultrasonik semakin pesat. Dari menggunakan satu pengirim dan satu penerima yang lebih dikenal dengan Single Transmitter Single Receiver (STSR) menjadi banyak pengirim dan banyak penerima atau Multiple Transmitter Multiple Receiver (MTMR) [5]. Dengan penggunaan konsep MTMR tersebut, dapat dilakukan perbandingan yang efektif pada masing-masing sensor ultrasonik yang digunakan untuk mendeteksi kecacatan benda. Bagian terpenting dari konsep NDT dengan ultrasonik adalah bagaimana membuat pembangkit pulsa elektroniknya. Dengan mengutamakan kelebihan dibandingkan dengan sumber pulsa lain sepert AFG, diantaranya portable, bahaya radiasi kecil, harga relatif lebih murah, lebih banyak variasi frekuensi yang dapat dihasilkan, dan penggunaan catu daya yang kecil maka akan digunakan mikrokontroler sebagai pembangkit pulsa elektroniknya [6].

Keberhasilan sinyal menembus beton yang paling utama dipengaruhi oleh rangkaian pembangkit pulsa elektronik yang telah dibuat dan penguat sinyalnya. Penguat sinyal terdiri dari penguat tegangan dan penguat daya. Berdasarkan latar belakang diatas maka dalam penelitian ini akan diimplementasikan pembangkit pulsa elektronik berbasis mikrokontroler untuk konsep Multiple Transmitter sensor ultrasonik.

\section{METODE PENELITIAN}

\subsection{Analisis Sistem}

Non Destructive Testing (NDT) adalah pengujian material tanpa menyebabkan kerusakan pada material tersebut. Pengujian ini bertujuan untuk mendeteksi dan menentukan lokasi, ukuran dan karakteristik lubang [7]. Sistem metode ultrasonik umumnya terdiri dari pulser/receiver, transducer dan peralatan display. Gelombang ultrasonikmemiliki frekuensi di atas jangkauan dengar manusia (di atas $20 \mathrm{kHz}$ ) [8]. Pulser/receiver adalah peralatan elektronik yang dapat menghasilkan pulsa listrik tegangan tinggi. Dikendalikan oleh pulser, transducer membangkitkan energi ultrasonik frekuensi tinggi. Energi suara ditransfer dan menjalar melalui 
material dalam bentuk gelombang. Bila terdapat discontinuitas (seperti crack) sepanjang jalur gelombang, sebagian energi akan dipantulkan kembali dari permukaan cacat. Suatu diskontinuitas akan memantulkan gelombang ultrasonic yang diaplikasikan, sehingga pada alat pencatat gelombang pantul dicatat adanya pulsa dari gelombang pantul yang bukan dari permukaan benda uji. Sinyal gelombang pantul lalu diubah menjadi sinyal listrik oleh transducer dan ditampilkan pada layar. Waktu tempuh sinyal dapat diubah langsung menjadi jarak yang ditempuh sinyal. Semakin pendek jarak lubang pada benda padat maka hasil tegangan dari amplitude yang diperoleh semakin besar [9]. Gelombang ultrasonik adalah gelombang bunyi yang mempunyai frekuensi diatas batas pendengaran manusia.

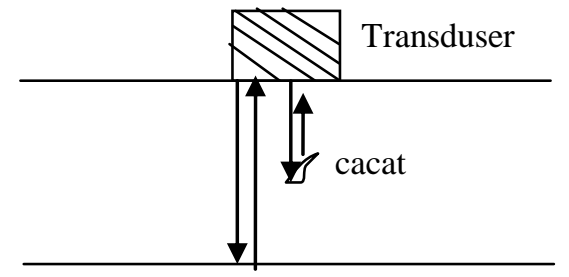

Gambar 1 NDT Dengan Sensor Ultrasonik

Suatu sinyal gelombang sinus secara garis besar terdiri dari periode, fase gelombang dan amplitudo. Periode adalah waktu yang dibutuhkan untuk melakukan satu gelombang. Amplitudo adalah simpangan terbesar dari gelombang [10]. Sedangkan fase dalam suatu gelombang menentukan kecepatan perulangan pada setiap satu kali pulsa clock. Rumus yang digunakan untuk menentukan fase gelombang menurut datasheet ditunjukkan pada persamaan (1).

$$
\mathrm{f}_{\text {out }}=(\Delta \text { phase } \mathrm{x} \text { CLKIN }) / 2^{32}
$$

$$
\Delta \text { phase }=\mathrm{f}_{\text {out }} \times 2^{32} / \text { CLKIN }
$$

dengan CLKIN adalah input referensi frekuensi clock dalam MHz. $\mathrm{f}_{\text {out }}$ adalah output sinyal dalam MHz.

Pada datasheet AD9850, telah ditampilkan untuk pengaturan berapa clock yang diperlukan pada masing-masing pin yang digunakan. Seperti yang diperlihatkan pada Gambar 2 di bawah.

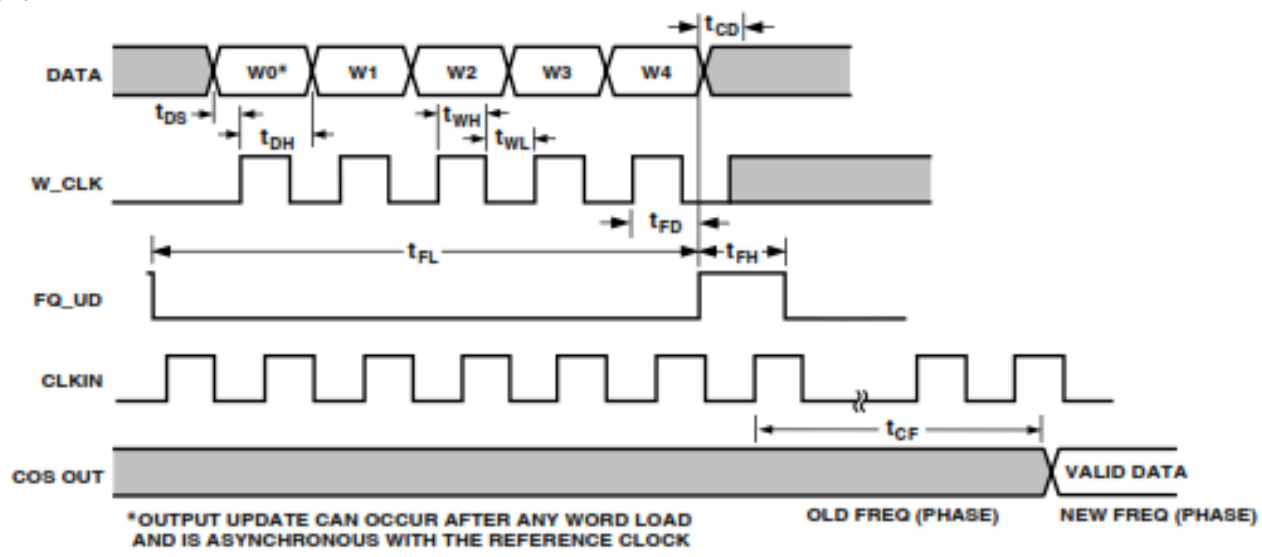

Gambar 2 Konfigurasi clock pada AD9850

Pada pemrograman clock ini menggunakan mode paralel. Pada mode paralel, register diisi oleh data 8 bit bus. Untuk mengisi penuh 40 bit word memerlukan lima kali perulangan 8 bit word. Sinyal dari pin W_CLK dan pin FQ_UD digunakan untuk pengalamatan dan isi dari register. Saat adanya clock pada pin FQ_UD akan mengisi lebih dari 40-bit data word pada AD9850 dan akan mereset alamat yang dituju pada register pertama. Kemudian pin W_CLK 
mendapat clock akan mengisi 8-bit data words. Dan memindahkan ke register berikutnya. Setelah lima kali mengisi, W_CLK akan mengalami penolakan apabila akan mengisi data lagi sebelum pin FQ_UD melakukan reset pada penunjuk alamat pada register pertama.

\subsection{Rancangan sistem}

Sistem yang akan dirancang untuk penelitian ini merupakan sistem yang dapat melakukan pendeteksian cacat beton menggunakan sensor ultrasonik dengan metode pulsa pantul. Skema blok dari sistem pembangkit pulsa tiga sensor ditunjukkan pada Gambar 3. Untuk mengetahui kinerja dari sistem elektronik tersebut diperlukan osiloskop digital 2 channel yang dipasang pada transmitter dan receiver.

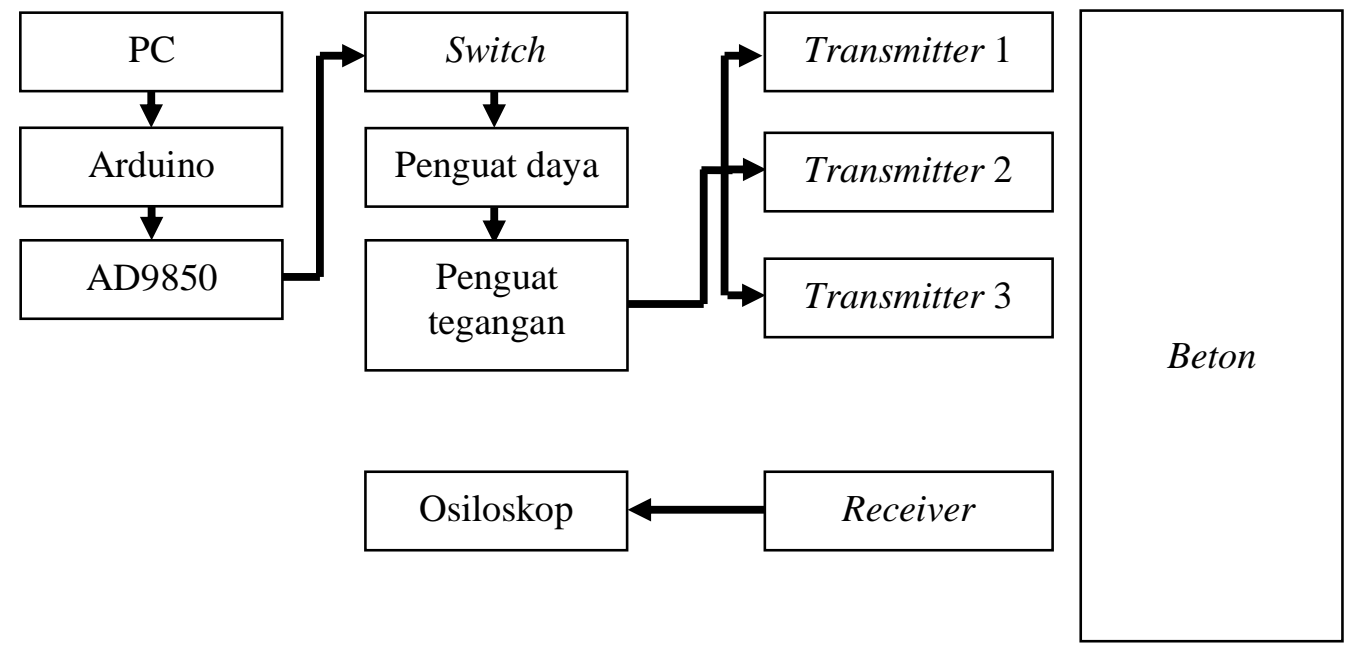

Gambar 3 Skema blok dari sistem pembangkit pulsa tiga sensor

Bagian transmitter ini diawali oleh bagian PC atau komputer yang terhubung melalui kabel serial ke mikrokontroler. Pengguna akan memberikan masukan sebuah nilai frekuensi yakni $\pm 40 \mathrm{kHz}$. Mikrokontroler akan mengirimkan instruksi-instruksi kepada modul DDS AD9850 agar mengubah nilai yang telah dimasukkan oleh pengguna menjadi sebuah bentuk gelombang sinus. Untuk memilih transmitter yang ingin digunakan dapat mengaktifkan salah satu switch yang terpasang. Selanjutnya gelombang atau sinyal yang dihasilkan akan dikuatkan oleh bagian penguat transmitter yang terdiri dari penguat daya dan penguat tegangan. Penguat daya digunakan untuk menaikkan tegangan beserta arus dari sinyal sumber. Penguat tegangan digunakan untuk menaikkan tegangan menjadi beberapa kali lipat dari hasil penguatan daya. Hal ini dilakukan karena sinyal yang dipancarkan oleh bagian transmitter masih terlalu kecil dan tidak dapat menembus beton. Sinyal yang telah berhasil menembus beton akan terpantul kembali menuju receiver. Pada bagian receiver ini dihubungkan ke penampil yaitu osiloskop. Gambar 4 menunjukkan skematik rangkaian bagian penguat transmitter.

Rangkaian audio amplifier LM386 digunakan untuk menguatkan daya dari keluaran AD9850 menuju trafo ferit. IC ini merupakan IC audio amplifier yang dapat dioperasikan pada tegangan yang rendah, yakni $5-15 \mathrm{~V}$. Sekaligus dapat menguatkan sinyal frekuensi di atas frekuensi audio yaitu di atas $20 \mathrm{kHz}$. Hasil penguatan dari IC tergantung rangkaian yang digunakan. Secara default kaki 2 dan 4 IC di GND kan maka akan terjadi penguatan 20x dari nilai masukannya. Trafo yang dibuat beroperasi pada frekuensi tinggi maka inti trafo yang digunakan harus bahan ferit untuk mengurari rugi arus eddy dan histerisis [11]. 


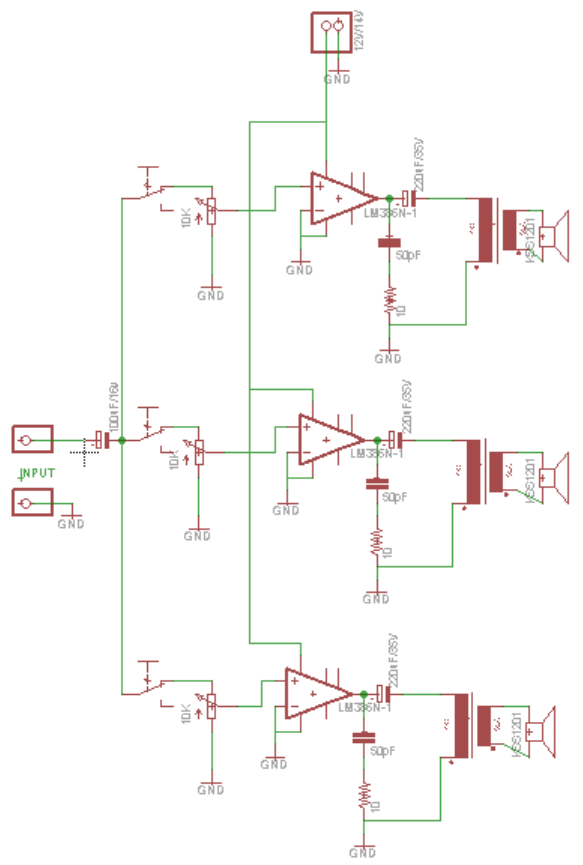

Gambar 4 Skematik bagian transmitter

Sedangkan bagian pembentuk sinyal sinus pin arduino dan pin AD9850 diperlihatkan pada Gambar 5 (a) dan 5 (b).

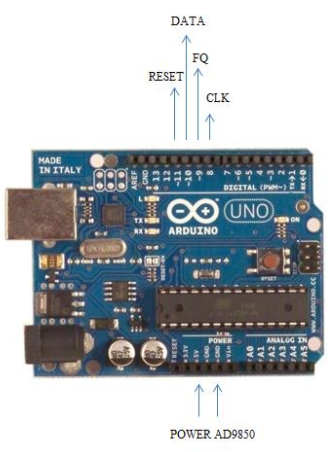

(a)

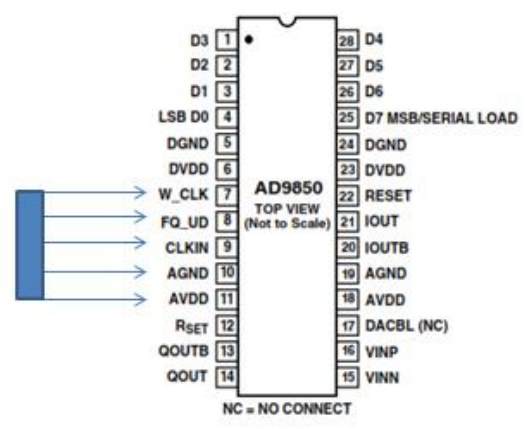

(b)

Gambar 5 Pin Arduino (a) dan pin AD9850 (b)

\subsection{Bahan uji}

Benda padat uji yang digunakan adalah sebuah beton yang terdiri dari campuran semen, pasir dan air yang memiliki dimensi yang sama serta ukuran cacat yang berbeda antara satu dan yang lainnya. Perbandingan banyaknya campuran semen, pasir dan air adalah 1:1:1. Dengan ukuran cacat buatan seperti pada Tabel 1 .

Tabel 1 Benda padat uji

\begin{tabular}{|c|c|c|c|c|}
\hline No. & Panjang $(\mathrm{cm})$ & Lebar $(\mathrm{cm})$ & Tinggi $(\mathrm{cm})$ & Panjang cacat buatan $(\mathrm{cm})$ \\
\hline 1 & 21 & 9 & 6,5 & 5,5 \\
\hline 2 & 21 & 9 & 6,5 & 11,5 \\
\hline 3 & 20 & 10 & 8 & 2 \\
\hline
\end{tabular}




\subsection{Implementasi}

2.3.1 Implementasi elektronik transmitter

Implementasi elektronik pada sistem pendeteksi cacat beton ini terdiri dari rangkaian board Arduino, rangkaian audio amplifier LM 386, dan penguat tegangan transformator inti ferit. Penempatan elektronis diletakan pada kotak yang didesain untuk meletakkan beberapa rangkaian yang digunakan, seperti: rangkaian audio amplifier LM 386, transformator inti ferit, serta sensor ultrasonik yang digunakan sebagai transmitter. Receiver dipasang terpisah. Implementasi elektronik diperlihatkan pada Gambar 6.

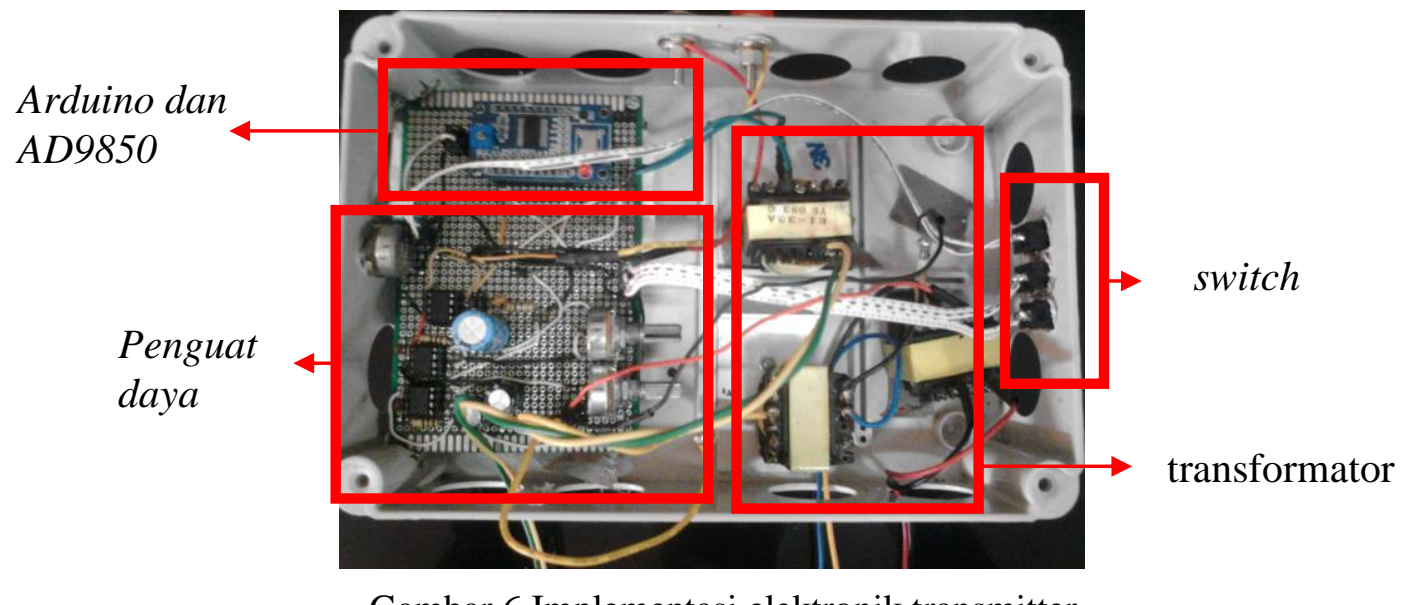

Gambar 6 Implementasi elektronik transmitter

\subsubsection{Implementasi beton dengan cacat buatan}

Penulis membuat objek berdasarkan rancangan objek yang sudah rancangkan sebelumnya. Tabel 1 menunjukan ukuran objek dan panjang cacat yang sudah siap untuk dilakukan pengujian. Ketiga objek tersebut memiliki variasi jarak lubang pada benda padat yang berbeda - beda. Gambar 7 menunjukkan beton yang dibuat penulis dengan variasi jarak lubang yang berbeda tampak depan.

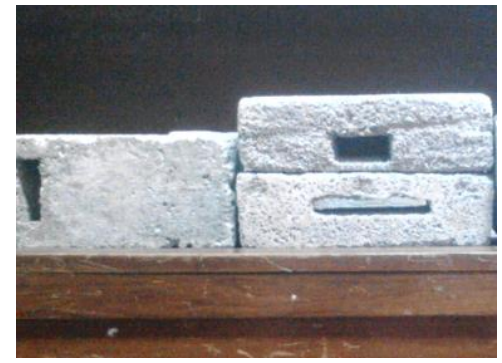

Gambar 7 Implementasi beton dengan cacat

\section{HASIL DAN PEMBAHASAN}

\section{$2.4 \quad$ Pengujian mikrokontroler dan AD9850}

Pada pengujian ini adalah pengujian program yang telah dibuat dan dimasukkan pada mikrokontroler. Nilai frekuensi dimasukkan melalui serial Arduino. Selain itu diukur besarnya gelombang yang dihasilkan oleh mikrokontroler yang terhubung ke AD9850 yang terukur dalam tegangan dengan frekuensi yang berbeda-beda. Gambar 8 menunjukkan nilai tegangan maksimal dan frekuensi yang dihasilkan oleh AD9850. 


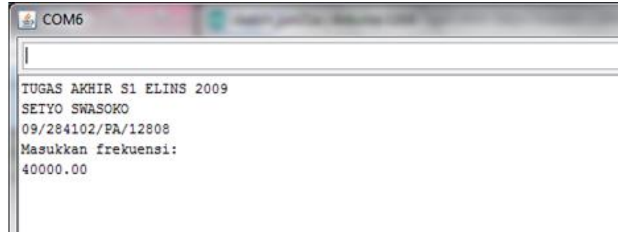

(a)

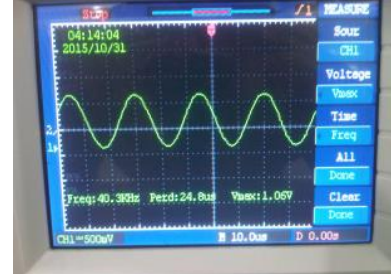

(b)

Gambar 8 (a) Serial Arduino (b)Tegangan maksimal dan frekuensi yang dihasilkan AD9850

Frekuensi pada mikrokontroler diatur dari pada $40 \mathrm{kHz}$. Keluaran amplitudo frekuensi minimal yang dapat dihasilkan adalah $0 \mathrm{~V}$ sedangkan maksimalnya adalah $\pm 1,04 \mathrm{~V}$.

\subsection{Pengujian penguat daya transmitter}

Rangkaian LM386 akan menguatkan hasil keluaran modul menjadi 20 kali dari nilai masukannya. Hasil dari penguatan yang terjadi pada LM386 dipengaruhi oleh besar tegangan yang dimasukkan pada kaki VCC LM386. Dari datasheet LM386, nilai maksimal VCC adalah $15 \mathrm{~V}$. Akan tetapi untuk membuat agar LM386 tidak mudah rusak, tegangan VCC dikurangi menjadi $\pm 14 \mathrm{~V}$. Hail penguatan gelombang diperlihatkan Gambar 9.

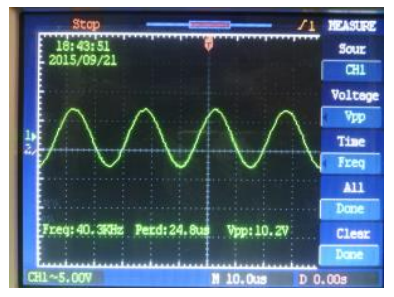

Gambar 9 Penguatan amplitudo LM386

Apabila potensiometer masukan diperbesar lagi sehingga mendekati $\pm 1,04 \mathrm{~V}$ maka LM386 akan mendekati titik maksimal penguatan tegangan yang sama dengan VCC dari kaki 6 LM386 yaitu $14 \mathrm{~V}$. Dan akhirnya akan memotong sinyal hasil penguatan karena rangkaian opamp menjadi jenuh. Inilah yang disebut saturasi pada gelombang frekuensi. Hasil penguatan tegangan gelombang maksimal adalah 10,2 V sebelum gelombang tersebut terpotong.

\subsection{Pengujian penguat tegangan transmitter}

Pengujian sub bab ini adalah mengukur tegangan atau amplitudo gelombang sinus yang sudah dikuatkan tegangannya dengan menggunakan trafo inti ferit. Hasil penguatan trafo int ferit diperlihatkan pada Gambar 10.

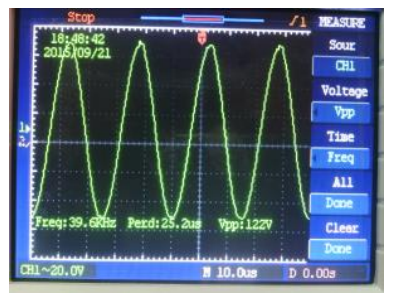

Gambar 10 Penguatan amplitudo dengan trafo inti ferit

Sinyal masukan dari LM386 setelah dihubungkan ke kaki sekunder trafo inti ferit menghasilkan penguatan tegangan hingga lebih dari $100 \mathrm{~V}$. Besarnya penguatan tegangan yang terjadi pada trafo dipengaruhi oleh perbandingan jumlah lilitan primer dan sekunder trafo. 
Gelombang dapat divariasi tegangannya dengan maksimal sesuai penguatan LM386 yaitu $\pm 14 \mathrm{~V}$. Variasi nilai tegangan dapat dilakukan dengan memutar potensiometer di kaki 3 LM386.

\subsection{Pengujian transmitter}

Pada sub bab ini bagian keluaran dari trafo yang digunakan dihubungkan ke sensor yang digunakan. Tiga sensor dipasang pada kotak yang dibuat dan diberi saklar pada masingmasing LM386. Fungsi dari pengujian ini adalah mencari tegangan maksimal yang dapat dipancarkan oleh tiga jenis transmitter yang berbeda. Dari hasil pengujian, akan diambil sensor yang terbaik dalam memancarkan sinyal frekuensi $40 \mathrm{kHz}$. Tabel 2 memperlihatkan hasil masing-masing sensor receiver yang ditempelkan langsung ke bagian transmitter. Hasil yang diperoleh sangat bervariasi tergantung sensor yang digunakan. Potensiometer diputar agar trafo mengahsilkan nilai output Vpp $10 \mathrm{~V}$ terlebih dahulu dan diamati pada osiloskop besar Vpp yang diterima receiver. Pengujian dilanjutkan dengan variasi tegangan hingga 100V.

Tabel 2 Pengujian sensor

\begin{tabular}{|c|c|c|c|}
\hline \multirow{2}{*}{ Vpp (V) } & \multicolumn{3}{|c|}{ Vpp receiver (V) } \\
\cline { 2 - 4 } & Non modul & Modul & Modul \\
\cline { 2 - 4 } & $\begin{array}{c}\text { Transmitter } \\
40 \mathrm{kHz}\end{array}$ & HCSR04 & SRF04 \\
\hline 10 & 4.4 & 8 & 10 \\
\hline 20 & 13.6 & 24.4 & 20 \\
\hline 30 & 20 & 30 & 39 \\
\hline 40 & 25.6 & 36.8 & 51.6 \\
\hline 50 & 29.6 & 39 & 52.4 \\
\hline 60 & 30.8 & 44 & 60 \\
\hline 70 & 36.4 & 46 & 67.2 \\
\hline 80 & 20.8 & 32 & 36 \\
\hline 90 & 20.8 & 30 & 34 \\
\hline 100 & 7.4 & 7.7 & 7.9 \\
\hline
\end{tabular}

Kualitas sensor terbaik apabila diamati dari tabel adalah milik SRF04. Ketika sensor diberikan tegangan masukan $70 \mathrm{~V}$, terlihat sensor SRF04 sudah mulai tidak dapat mengirimkan sinyal dengan tegangan tersebut. Ini mengindikasikan Vpp input maksimum hanya mencapai $\pm 60 \mathrm{~V}$. Oleh karena itu digunakan tiga buah transmitter milik SRF04. Hasil pengujian masingmasing transmitter SRF04 dapat diamati pada Tabel 3.

Tabel 3 Pengujian sensor SRF04

\begin{tabular}{|c|c|c|c|}
\hline \multirow{2}{*}{ Vpp (V) } & \multicolumn{3}{|c|}{ Vpp (V) } \\
\cline { 2 - 4 } & Sensor 1 & Sensor 2 & Sensor 3 \\
\hline 10 & 14 & 14,4 & 14,4 \\
\hline 20 & 25,6 & 26 & 25,6 \\
\hline 30 & 34,4 & 34 & 34 \\
\hline 40 & 41,6 & 38,4 & 40 \\
\hline 50 & 52 & 51,2 & 51.2 \\
\hline 60 & 60 & 59,2 & 60 \\
\hline
\end{tabular}

IJEIS Vol. 7, No. 2, October 2017 : $197-208$ 
2.8 Pengujian transmitter pada benda uji

Pengujian pada sub bab ini adalah dengan cara menembakkan frekuensi $40 \mathrm{KHz}$ dengan amplitudo $\pm 60 \mathrm{~V}$ ke beton untuk mendeteksi seberapa panjang cacat didalam beton yang telah dibuat. Pembacaan sensor receiver dengan metode indirect atau meletakkan sensor receiver di sebelah transmitter. Ketiga sensor akan dihidupkan secara bergantian dengan switch. Gambar 11 menunjukkan grafik hasil pendeteksian cacat.
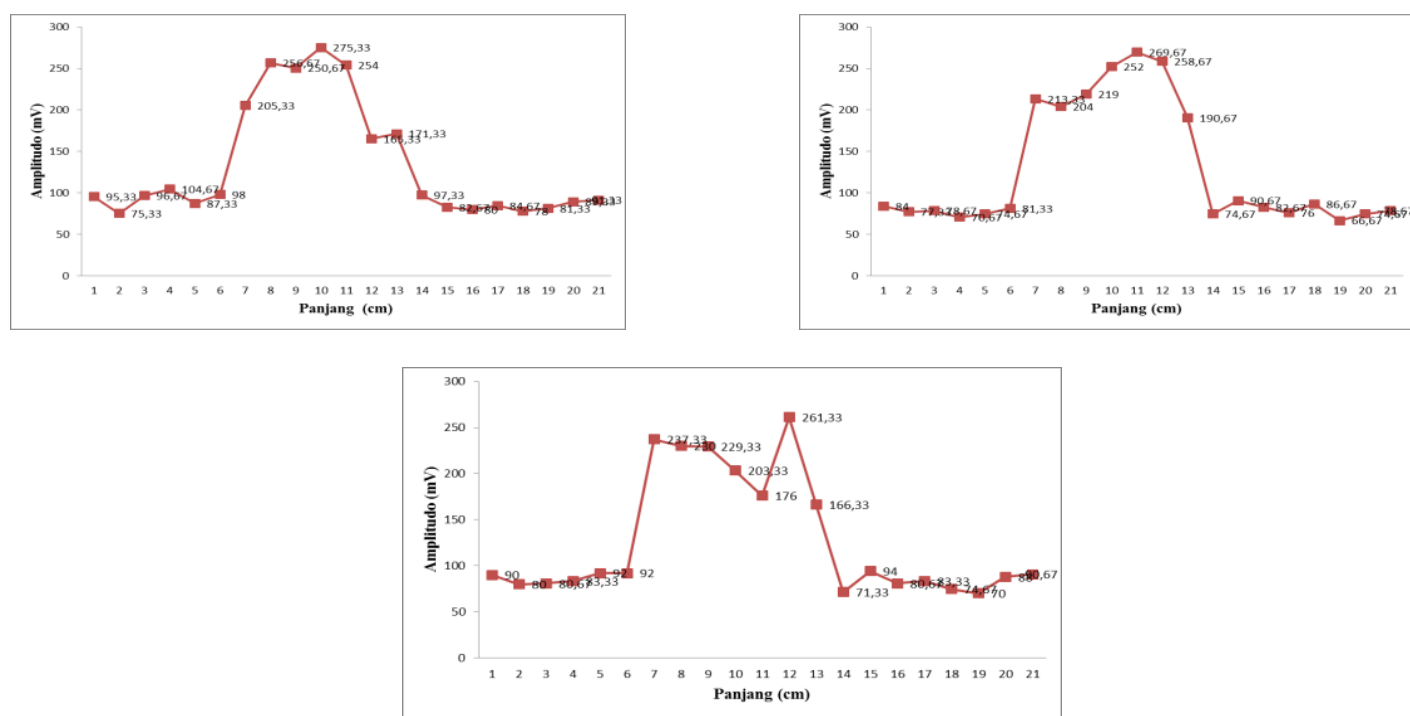

(a)
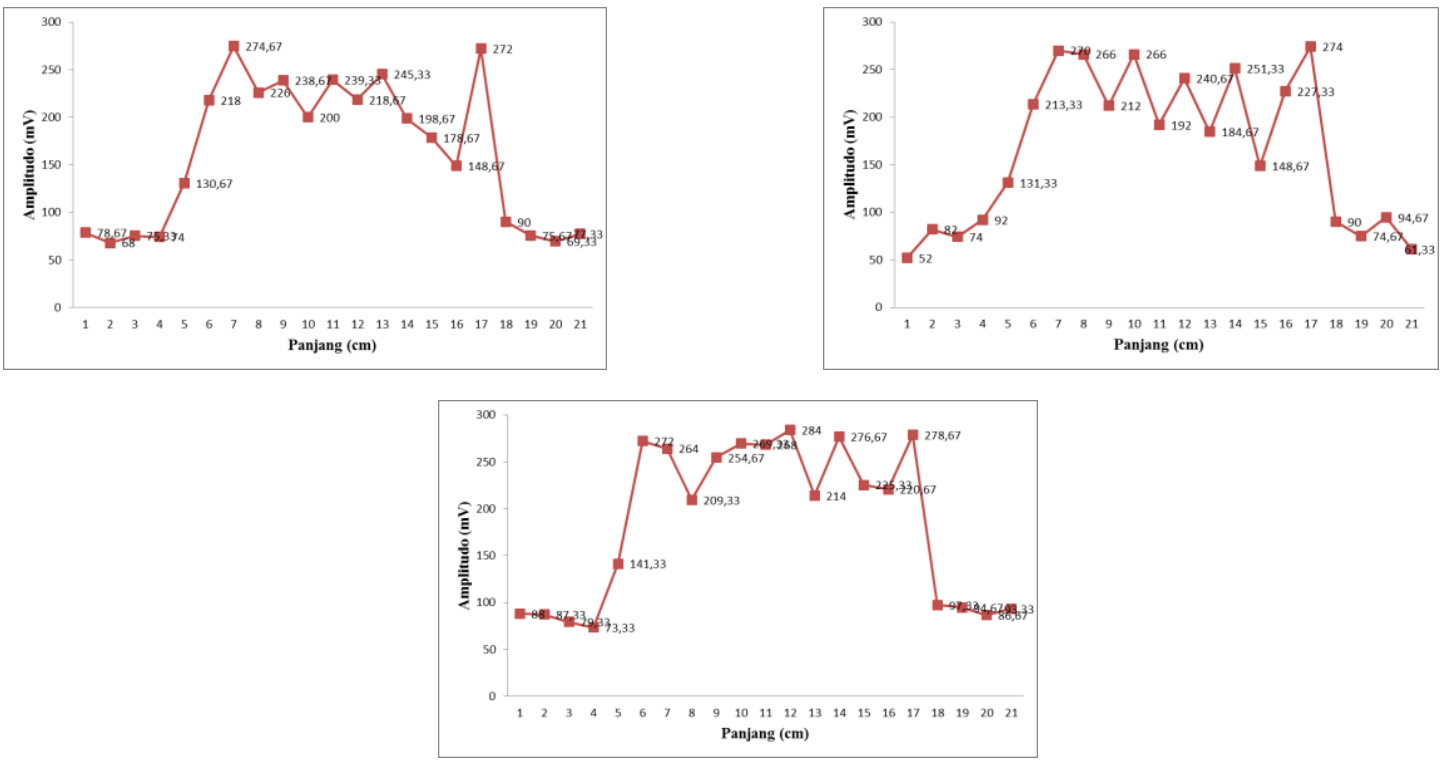

(b)
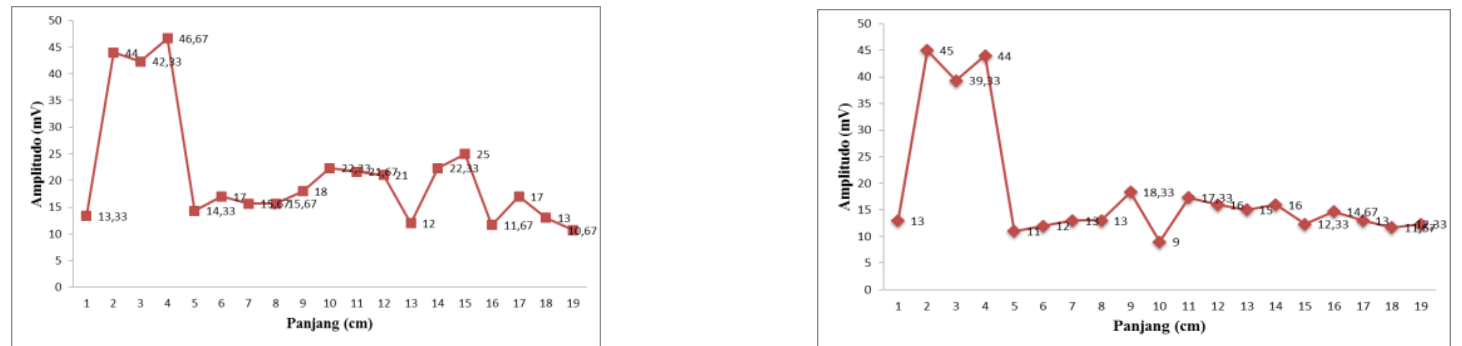


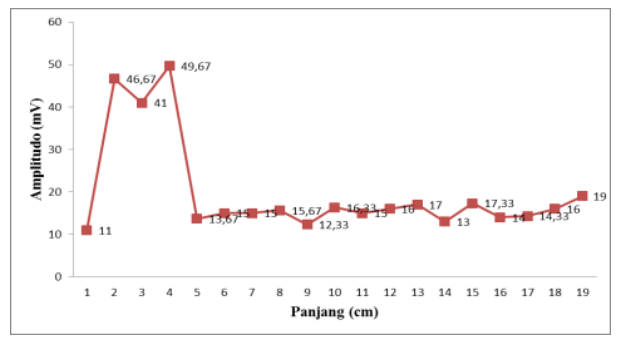

(c)

Gambar 11 (a) Grafik deteksi cacat beton pertama oleh ketiga sensor (b) Grafik deteksi cacat beton kedua oleh ketiga sensor (a) Grafik deteksi cacat beton ketiga oleh ketiga sensor

Gambar 11 merupakan grafik hasil pengukuran yang di lakukan terhadap 3 beton yang digunakan. Dari hasil tersebut dapat dilakukan analisis untuk mengetahui ukuran kecacatan yang dideteksi oleh sensor dengan malakukan analisis amplitudo maupun tegangan yang diperoleh dalam setiap pendeteksian yang dilakukan. Sesuai dengan teori bahwa jarak tempuh dari gelombang akan mempengaruhi nilai dari amplitudo maupun tegangan yang diperoleh maka dari ke tiga hasil tersebut dapat disimpulkan bahwa ketika amplitudo maupun tegangan yang diperoleh dari gelombang pantul yang dipantulkan oleh beton memiliki perbedaan yang segnifikan pada setiap variasi pengukuran bahwa nilai amplitudo maupun tegangan meningkat, maka disitulah indikasi bahwa sensor mendeteksi adanya cacat. Sehingga untuk mengetahui ukuran dari pada cacat yang berada dalam benda padat maka hanya perlu dilakukan analisis dari variasi pengukuran senti berapa hingga senti berapa amplitudo maupun tegangan mengalami kenaikan yang segnifikan.

Dari beberapa pengujian di atas dapat dilihat dan diamati pada bagian yang rata-rata amplitudonya, bahwa adanya cacat yang terdapat pada beton amplitudonya semakin besar karena jarak pantulmya yang semakin dekat. Apabila cacat semakin jauh dari pusat pemancar gelombang maka hasil pembacaan amplitudonya akan mengecil. Sesuai dengan teori bahwa jarak tempuh dari gelombang akan mempengaruhi nilai dari amplitudo maupun tegangan yang diperoleh maka dari tiga hasil tesebut dapat disimpulkan ketika amplitudo maupun tegangan yang diperoleh dari gelombang pantul yang dipantulkan oleh beton memiliki perbedaan yang signifikan pada setiap variasi pengukuran bahwa nilai amplitudo gelombang meningkat, maka disitulah indikasi bahwa sensor mendeteksi adanya cacat. Sehingga untuk mengetahui ukuran daripada cacat yang berada dalam benda padat maka hanya perlu dilakukan analisis variasi pengukuran berapa centimeter hingga berapa centimeter amplitudo sinyal mengalami kenaikan yang signifikan seperti pada tabel pengujian beton yang cacat.

Tabel 4 Hasil perbandingan pembacaan sensor dengan panjang cacat sebenarnya

\begin{tabular}{|c|c|c|c|c|c|c|c|c|c|c|}
\hline \multirow[t]{2}{*}{ No. } & \multirow[t]{2}{*}{$\begin{array}{l}\text { Panjang } \\
(\mathrm{cm})\end{array}$} & \multirow[t]{2}{*}{$\begin{array}{c}\text { Lebar } \\
(\mathrm{cm})\end{array}$} & \multirow[t]{2}{*}{$\begin{array}{l}\text { Tinggi } \\
(\mathrm{cm})\end{array}$} & \multirow[t]{2}{*}{$\begin{array}{c}\text { Panjang cacat } \\
\text { buatan }(\mathrm{cm})\end{array}$} & \multicolumn{3}{|c|}{$\begin{array}{l}\text { Ukuran terdeteksi } \\
\text { sensor } \\
(\mathrm{cm})\end{array}$} & \multicolumn{3}{|c|}{ Selisih (cm) } \\
\hline & & & & & S1 & S2 & S3 & S1 & S2 & S3 \\
\hline 1 & 21 & 9 & 6,5 & 5,5 & 6 & 6 & 6 & 0,5 & 0,5 & 0,5 \\
\hline 2 & 21 & 9 & 6,5 & 11,5 & 12 & 12 & 12 & 0,5 & 0,5 & 0,5 \\
\hline 3 & 20 & 10 & 8 & 2 & 0 & 0 & 0 & 0 & 0 & 0 \\
\hline
\end{tabular}

Tabel 4 merupakan tabel analisis hasil pengukuran sensor ultrasonik yang diperoleh berdasarkan hasil pengujian beton 1, 2, dan 3. Dari perhitungan diperoleh besar selisih untuk sensor 1 pada beton pertama $0,5 \mathrm{~cm}$, sensor 2 adalah $0,5 \mathrm{~cm}$, dan sensor 3 adalah $0,5 \mathrm{~cm}$. Dan dari perhitungan juga diperoleh besar selisih untuk sensor 1 pada beton kedua $0,5 \mathrm{~cm}$, sensor 2 
adalah $0,5 \mathrm{~cm}$, dan sensor 3 adalah $0,5 \mathrm{~cm}$. Sedangkan untuk beton ketiga, semua sensor mendeteksi dengan benar panjang cacatnya. Meskipun nilai dari tegangan masing-masing sensor berbeda, tapi pembacaannya memiliki nilai selisih yang sama. Untuk masing-masing sensor yaitu pengujian deteksi ukuran pada setiap benda padat dapat dilihat berdasarkan kenaikan amplitudo pada masing-masing pengujian. Data yang menyebutkan bahwa sensor dapat mendeteksi cacat adalah ketika amplitudo maupun tegangan mengalami kenaikan yang signifikan sehingga dari variasi pengukuran yang dilakukan dapat diketahui hasil bacaan sensor terhadap ukuran kecacatan pada setiap benda uji. Alat yang dibuat tidak dapat dihitung nilai errornya, karena pada hasil pembacaan sensor dari alat yang dibuat sangat tergantung dari komposisi beton dan tebal beton yang diujikan. Seperti yang terjadi pada beton 3, komposisi beton 3 lebih tebal dari beton 1 dan beton 2 sehingga nilai Vpp yang dihasilkan juga lebih kecil dari Vpp pada saat tinggi beton hanya $6,5 \mathrm{~cm}$. Hal ini juga dikarenakan sensor transmitter yang digunakan hanya terbatas pada Vpp yang maksimum $\pm 60 \mathrm{~V}$. Jika ingin memperbesar tegangan Vpp nya tidak dapat dilakukan, karena dapat merusak transmitter.

\section{KESIMPULAN}

Dari penelitian yang dilakukan, dapat diambil beberapa kesimpulan sebagai berikut:

1. Telah berhasil merancang dan mengimplementasikan alat untuk mengetahui pengaruh lebar cacat beton dengan bentuk gelombang sensor ultrasonik dan menampilkan hasil pantulannya dengan osiloskop.

2. Dari hasil pengujian metode sinyal pantul dengan melakukan pergeseran benda padat terhadap sensor dengan kelipatan $1 \mathrm{~cm}$ sisi panjang beton dapat menentukan panjang dari kecacatan beton uji.

3. Output tegangan maksimal AD9850 adalah $\pm 1,04 \mathrm{~V}$.

4. Output tegangan maksimal LM386 adalah $\pm 14 \mathrm{~V}$.

5. Output tegangan maksimal trafo inti ferit adalah $\pm 170 \mathrm{~V}$.

6. Input tegangan maksimal transmitter SRF04 adalah $\pm 60 \mathrm{~V}$.

7. Ukuran hasil pengujian pada ketiga panjang beton memiliki selisih sebagai berikut:

a. Beton pertama

- Sensor $1=0,5 \mathrm{~cm}$.

- Sensor $2=0,5 \mathrm{~cm}$.

- Sensor $3=0,5 \mathrm{~cm}$.

b. Beton kedua

- Sensor $1=0,5 \mathrm{~cm}$.

- Sensor $2=0,5 \mathrm{~cm}$.

- Sensor $3=0,5 \mathrm{~cm}$.

c. Beton ketiga

- Sensor $1=0 \mathrm{~cm}$.

- Sensor $2=0 \mathrm{~cm}$.

- Sensor $3=0 \mathrm{~cm}$.

8. Amplitudo gelombang akan mengecil apabila jarak pantul semakin jauh, sebaliknya amplitudo semakin besar apabila jarak pantul semakin dekat.

\section{SARAN}

Untuk penelitian lebih lanjut dengan tema yang sama, disarankan untuk melakukan hal-hal sebagai berikut :

1. Beton yang digunakan harus lebih bagus dan rata.

2. Dapat mengembangkan program untuk pembangkit gelombang dengan mikrokontroler yang lebih baik.

3. Menggunakan sensor ultrasonik yang dapat digunakan pada tegangan tinggi. 


\section{DAFTAR PUSTAKA}

[1] T. Nur Syahril Sidiq, A. Rouf, and T. Wahyu Supardi, "Sistem Deteksi Bentuk Kecacatan Benda Padat Menggunakan Teknik Variasi Sudut Ultrasonik," IJEIS (Indonesian J. Electron. Instrum. Syst., vol. 6, no. 1, p. 69, Apr. 2016 [Online]. Available: https://jurnal.ugm.ac.id/ijeis/article/view/10773. [Accessed: 23-Apr-2017]

[2] Kouche, A.E. dan Hassanein, H.S., Ultrasonic Non-Destructive Testing (NDT) Using Wireless Sensor Networks, The $3^{\text {rd }}$ International Conference on Ambient Systems, Networks and Technologies (ANT), Vol. 10, Hal. 136-143.

[3] Yatarif, N.W., 2008, Karakterisasi Sinyal Akustik Untuk Mendeteksi Keabnormalan Jaringan Tubuh Menggunakan Ultrasonik, Skripsi, Fakultas Ilmu Pengetahuan Alam, UI, Jakarta.

[4] Clorennec, D., Royer, D. dan Catheline, S., 2002, Saw Propagation on Cylindrical Part Using Laser Ultrasonics: Applications to Crack Detection, Proceedings Ultrasonics Symposium, 8-11 Oktober.

[5] Sonbul, O., Popejoy, P., dan Kalashnikov, A., N., 2012, Ultrasonic Sensor Array for Remote Sensing of Profiles of Bulk Materials, Instrumentation and Measurement Technology Conference (I2MTC), 13-16 Mei.

[6] Suryono, Kusminarto, dan Suparta, GB., 2010, Rancang Bangun Pembangkit Pulsa Ultrasonik Untuk Material Padat Berbasis Mikrokontroler, Prosiding Pertemuan Ilmiah XXIV HFI Jateng \& DIY, Semarang, 10 April.

[7] Subiyanto, L. dan Sardjono, T. A., 2012, Deteksi Cacat Pada Material Baja Menggunakan Ultrasonik Non-Destructive Testing dengan Metode Continous Wavelet Transform, Seminar Nasional Teknologi Informasi dan Komunikasi Terapan, Semarang, 23 Juni.

[8] Alfansuri, A. F., 2012, Identifikasi Chilling Injury Buah Alpukat (Persea Americana Mill) dengan Gelombang Ultrasonik, Skripsi, Fakultas Teknologi Pertanian, Institut Pertanian Bogor, Bogor.

[9] I. Dwicahyo Pratomo, A. Rouf, and T. Wahyu Supardi, "Pengukuran Jarak Lubang Pada Benda Padat Menggunakan Sensor Ultrasonik," IJEIS (Indonesian J. Electron. Instrum. Syst., vol. 6, no. 1, p. 81, Apr. 2016 [Online]. Available: https://jurnal.ugm.ac.id/ijeis/article/view/10774. [Accessed: 25-Apr-2017]

[10] Zubaidah, S., Mahanal, S., Yuliati, L. dan Sigit, D., 2014, Ilmu Pengetahuan Alam SMP Kelas 8, Kementerian Pendidikan dan Kebudayaan, Jakarta.

[11] Darsono, Suyamto dan Nuraini, E., 2012, Desain Trafo Tegangan Tinggi Berfrekuensi Tinggi 40khz/17,5kv Untuk Stt Cockcroft Walton Mbe Lateks, IJMS, Vol. 14, Hal. 5-15. 